\title{
O Conhecimento Fonético Acústico-Articulatório e o Ensino de Língua Estrangeira
}

\author{
Acoustic-Articulatory Phonetic Knowledge \\ and Foreign Language Teaching
}

Cirineu Cecote STEIN *

Resumo: A sobreposição de quadros fonêmicos de línguas diferentes evidencia fonemas que pertencem a um idioma, mas não a outro. Além disso, um mesmo fonema pode ser foneticamente realizado de formas diferentes em idiomas distintos. Considerando-se os estágios de desenvolvimento da capacidade perceptiva e articulatória do aprendiz de L2, alguns segmentos poderão ser pronunciados com maior ou menor acuidade. Neste trabalho, focaliza-se como o conhecimento teórico e o instrumental da fonética acústico-articulatória pode contribuir para otimizar o trabalho do professor na orientação à aquisição fonético-fonológica do aprendiz de L2.

Palavras-chave: Fonética acústico-articulatória. Ensino de L2.

Abstract: Although phonemic tables of different languages present similar phonemes, the realization of phonemes has its particularities in each language. For an L2 learner, the pronunciation of those segments may be more, or less, accurate, depending on the stage of development of his/her perceptual and articulatory capacity. This paper focuses on how the theoretical knowledge and the instrumental apparatus of the acoustic and articulatory phonetics can contribute to guiding the phonetic and phonologic acquisition of the L2 learner.

Key-words: Acoustic and articulatory phonetics; L2 teaching

* Doutor em Letras Vernáculas pela Universidade Federal do Rio de Janeiro. Professor Adjunto do Departamento de Letras Clássicas e Vernáculas da Universidade Federal da Paraíba. Contato: cirineu.stein@cchla.ufpb.br 


\section{Introdução}

As características fonético-fonológicas de uma língua contribuem para estabelecer a sua identidade. As peculiaridades dos arranjos fônicos ao longo da cadeia sonora permitem, por exemplo, que mesmo duas línguas de origem comum, muito próximas uma da outra, sejam reconhecidas como línguas diferentes. Aprender uma língua estrangeira (L2) implica adquirir a consciência e o domínio dessas peculiaridades, com a capacidade de reproduzi-las. Quanto mais elevada for essa capacidade do aprendiz, melhor será o seu desempenho, podendo mesmo vir a ser confundido com um falante nativo do idioma.

De uma forma geral, muitos professores de L2 tendem a relegar o ensino da pronúncia a um segundo plano, pelo menos se considerado de uma forma sistemática. Muitas vezes, esse ensino se dá a partir de uma visão impressionística, carente de sustentação teórica apropriada e de um instrumental que possa tornar o processo de ensino e aprendizagem mais fácil e eficiente. Sem dúvida, pode-se atingir um bom resultado dessa forma (como inúmeros exemplos o comprovam), mas a combinação do domínio dos mecanismos envolvidos na produção sonora da fala, da consciência de como se processam os gestos articulatórios típicos para a realização de cada fonema, e de um instrumental material apropriado permitirá uma maior eficiência no processo de aquisição, reduzindo não apenas o tempo total de aprendizagem, mas também as possíveis angústias, tanto do aprendiz quanto do professor, decorrentes de dificuldades que poderiam ser superadas de forma talvez mais imediata.

Este trabalho propõe a aplicação direta de alguns aspectos fonético-fonológicos ao cotidiano do ensino de L2. Inicialmente, indicase uma forma de identificar os segmentos da L2 potencialmente problemáticos para o aprendiz, a partir da sobreposição dos quadros fonêmicos das línguas envolvidas. Num segundo momento, faz-se um encaminhamento para a questão dos gestos articulatórios envolvidos na produção desses segmentos e as suas características acústicas, o que permitirá ao professor, valendo-se de programas computacionais específicos, diagnosticar os problemas que encontra em seus alunos e propor atividades e estratégias que facilitem a aquisição desse gestual. Num momento final, são apresentados três exemplos de aplicação 
dessa proposta, no nível do diagnóstico, envolvendo o desvozeamento e a aspiração de consoantes oclusivas e a qualidade vocálica, com base em realizações de informantes de origem estadunidense, alemã e francesa.

\section{A problemática da pronúncia de um segmento por um aprendiz de L2}

O aprendizado de uma L2 poderá visar, em princípio, apenas à habilidade de leitura, por exemplo, para fins acadêmicos. De uma forma mais completa, o aprendiz de L2 buscará, no entanto, o desenvolvimento da capacidade comunicativa considerando-se as habilidades básicas da fala, da audição e também da leitura. Nessa perspectiva mais completa, o processo de aprendizado, portanto, estará relacionado à aquisição não apenas da morfossintaxe e da semântica da L2, mas também do seu sistema fonético-fonológico.

Em estágios mais avançados, a expectativa é a de que o aprendiz apresente uma desenvoltura comunicativa que lhe permita um nível de fluência bastante próximo do evidenciado por falantes nativos daquela língua. Esse nível de fluência implicará o domínio de um vocabulário mais amplo, de construções morfossintáticas menos simples e, de forma mais evidente, de uma capacidade fonético-articulatória tal que sua pronúncia seja julgada bastante próxima da pronúncia nativa. Quanto menos marcas fonéticas estranhas à L2 esse aprendiz evidenciar, melhor será julgado seu desempenho. Naturalmente, essa eficiência fonética não estará vinculada apenas à realização exata dos fonemas da L2, mas também à configuração prosódica impressa às modalidades frasais, como um todo, e aos constituintes sintáticos, individualmente.

No nível fonético-fonológico, algumas línguas naturais possuem sistemas linguísticos aparentados entre si, o que, em princípio, facilitaria o processo de aquisição. Assumindo-se o referencial do português, é senso comum a noção de que o aprendizado de outra língua neolatina é mais acessível para o brasileiro do que o de uma língua de outra origem. Mesmo dentro do grupo das línguas neolatinas, o aprendizado do espanhol, por exemplo, tenderá a ser ainda mais acessível para o brasileiro, tamanha a semelhança entre as duas línguas. Naturalmente, não se deve desconsiderar que a especificidade articulatória dos fonemas 
no espanhol, quando desprezadas pelo aprendiz brasileiro (e vice-versa), levam a um estágio em que até é possível um nível consideravelmente alto de comunicação, mas que deixa muito evidente a não proficiência do aprendiz na L2 (para a problemática do estágio conhecido como de "interlíngua", cf. CARVALHO, 2002). Isso deixa evidente que, sem uma abordagem fonético-fonológica sólida, tanto da parte do professor quanto da parte do aprendiz, o domínio dos níveis morfossintático e semântico não se mostra suficiente para satisfazer uma semelhança efetiva com o falar nativo.

No nível sensório-motor, o aprendizado de L2 por um adulto tenderá a apresentar maiores dificuldades do que para uma criança. Como indica Eckman (2004), isso se deve a um decréscimo da acuidade necessária ao estabelecimento de novas categorias fonético-fonológicas, ainda que essa capacidade se mantenha por toda a vida. A implicação direta dessa capacidade de estabelecimento de novas categorias fonético-fonológicas está centrada tanto na identificação da ocorrência de um determinado segmento na cadeia fonológica quanto na capacidade motora de produzir os gestos articulatórios necessários à realização fonética desses segmentos. Um exemplo do primeiro caso seria a pronúncia do tap alveolar / / / por anglofalantes. Fonologicamente, esse segmento não ocorre no inglês; no entanto, em alguns dialetos, ele se manifesta como alofone das consoantes oclusivas alveolares / t d/ em posição pós-tônica, como em 'later' e 'ladder' (FACE, 2006, p. 48). Embora o anglofalante desses dialetos esteja habituado à realização [r] essa percepção é dificultada por não ser reconhecida pelo falante como um fonema da língua e, por conseguinte, não conseguir articulá-lo de forma satisfatória na L2, o que exemplifica o segundo caso acima.

Considere-se também que, mesmo para o falante nativo, a aquisição de determinados fonemas é mais tardia do que a de outros, o que reflete uma gradação de dificuldade dos gestos articulatórios envolvidos nos diversos segmentos. Lamprecht (1990, apud OLIVEIRA, 2006, p. 32-33) indica que, no português brasileiro, os sons plosivos e nasais são adquiridos antes dos fricativos que, por sua vez, são adquiridos antes das consoantes líquidas. Considerando-se as líquidas $(/ \mathrm{r} 1 \mathrm{~K} /$ ), as laterais antecedem as não laterais. A complexidade dos gestos articulatórios envolvidos na realização do tap alveolar / / / 
faz, portanto, que ele seja um dos últimos segmentos sonoros a serem adquiridos. Se essa dificuldade na aquisição de um segmento é natural em um falante nativo, é de esperar que esse mesmo segmento ofereça dificuldade especialmente significativa para o não nativo.

\section{A sobreposição dos quadros fonêmicos da L2 e da L1}

A identificação de quais fonemas da L2 potencialmente oferecerão maior dificuldade de aquisição pode se dar pela sobreposição do quadro fonêmico da L2 ao da L1 do aprendiz. Quando se faz essa sobreposição, considerando-se, por exemplo, o português e o alemão, é possível perceber que o sistema linguístico do alemão contém alguns fonemas estranhos ao sistema português. Por exemplo, o português não conta com uma consoante fricativa palatal desvozeada /ç/ (entre alguns outros segmentos). Por outro lado, o quadro fonêmico do português apresenta uma consoante nasal palatal / $\mathrm{n} /$, não presente no alemão. Potencialmente, portanto, o aprendiz brasileiro do alemão encontrará dificuldade ao realizar foneticamente o segmento /ç/, o mesmo ocorrendo com o aprendiz alemão do português ao adquirir o fonema $/ \mathrm{n} /$.

Como o aprendiz tem a necessidade de pronunciar os sons da L2, o referencial que assume é o que lhe está naturalmente disponível: o da sua própria L1 (ECKMAN, 2004). O repertório de sons da L1 será utilizado não só para a percepção, como também para a realização fonética dos fonemas da L2. No exemplo citado no parágrafo anterior, o brasileiro, ao ouvir, no alemão, a realização [ç], identifica-a com a consoante fricativa pós-alveolar [S], passando a pronunciar a palavra 'ich' como [if]. O alemão, por sua vez, ao pronunciar a palavra 'manhã', poderá se valer da combinação da consoante nasal alveolar com a vogal anterior alta, produzindo [man $\left.\mathrm{mi}^{\mathrm{l}} \mathrm{a}^{\mathrm{n}}\right]$, ou, por influência ortográfica, utilizar a combinação de [n] com a consoante fricativa glotal [h], produzindo [man'ha $\left.{ }^{\mathrm{n}}\right]$. A necessidade comunicativa, assim, é satisfeita no nível oral, mas, como sugere Sant'Anna (2008, p. 21), a incorporação dessas características da língua materna à L2 permite a identificação do "sotaque estrangeiro" do aprendiz.

A literatura especializada aponta vários exemplos em que a não interseção de quadros fonêmicos pode oferecer dificuldades durante 
o aprendizado de L2. No caso de estrangeiros aprendendo o português, a fricativa glotal desvozeada [h] é potencialmente complexa para, por exemplo, hispano e anglofalantes (DUTRA, 2008, p. 62). Os hispanofalantes tenderão a pronunciar a palavra 'rato', no português, como ['rato], empregando o trill alveolar, típico de seu sistema. Os anglofalantes tenderão à pronúncia ['uatu], ainda que seu sistema conte com a consoante /h/. O problema, nesse caso, está no fato de /h/, no inglês, ocorrer em posição fonológica (pré-vocálica) que, na ortografia, é representada pela letra “ $h$ ", como em 'house'; o trill alveolar [I] , por sua vez, ocorre em posição pré-vocálica em início e meio de vocábulo (e é representado ortograficamente pela letra " $r$ ", como em 'rat'). O anglofalante, assim, também por influência ortográfica, não consegue facilmente perceber que o fonema /h/, a que está habituado em seu próprio sistema, é representado ortograficamente de outra forma no português, além de poder ocorrer em outras posições fonológicas.

No caso de brasileiros aprendendo o inglês, uma dificuldade significativa pode se manifestar quando da realização da consoante aproximante lateral alveolar /1/ (SANT'ANNA, 2003, p. 66). Embora esse fonema integre ambos os quadros fonêmicos, a realização fonética em um e em outro idioma apresenta suas peculiaridades. No inglês, /1/ pode se realizar, por exemplo, por meio dos alofones [1], no início de sílaba ou em posição intervocálica; e [1], no final de sílaba ou diante de um fonema consonantal. Já no português brasileiro, embora haja a possibilidade de o alofone [1] se manifestar (em apenas algumas áreas geográficas restritas), o mais frequente é ocorrer a vocalização de /1/, produzindo-se um ditongo, como [ow], por exemplo. Assim, essa variação fonética do português brasileiro é transferida para a pronúncia de palavras inglesas, comprometendo a qualidade sonora final.

Essa transferência de características fônicas de um sistema a outro tem o objetivo de encontrar uma forma, ainda que aproximada, de realizar o fonema estranho à L1 do aprendiz. O uso dessas estratégias articulatórias, também conhecidas como estratégias de reparo (OLIVEIRA, 2006, p. 65), prevê inclusive a sua omissão, quando não é corretamente produzido. Isso ocorre também nos casos em que o próprio falante nativo da língua está adquirindo fonemas de maior 
complexidade. Como indicam Green et al. (2002) e Castro e Wertzner (2006 apud WERTZNER et al., 2007, p. 348), há a possibilidade, nos casos de a criança não possuir controle neuromuscular suficiente para a produção de determinados sons, que eles sejam produzidos com características peculiares, podendo ser afetados por componentes fonéticos, gerando-se imprecisões e distorções, e por componentes fonológicos, nos casos de simplificações por omissões ou substituições. Em a criança produzindo uma forma sonora, ainda que inapropriada, percebe-se a ausência de omissões, o que sugeriria a internalização do segmento no seu sistema fonológico, embora seja incapaz de produzilo adequadamente; enquanto que as distorções, por sua vez, indicariam uma dificuldade específica de produções. Se a criança substituir o segmento por outro, essa substituição, no entendimento das autoras, sugeriria um sistema fonológico alterado, ocorrendo a substituição do som alvo por outro já presente em seu inventário fonético e de realização mais acessível.

Eckman (2004) sugere que a extensão com que os sons são assimilados nas categorias fonéticas da L1 é determinada pelas características articulatórias que apresentam. Da mesma forma, o nível de assimilação de um som não nativo determina a capacidade do aprendiz de perceber o contraste entre o novo som e o de sua L1. Isso implicaria dizer, com Zimmer (2007), que os segmentos da L2 que não forem perceptualmente assimilados a uma categoria já presente na L1 serão passíveis de melhor discriminação; por conseguinte, sua realização tenderá a ser correta. No entanto, isso ocorrer dependerá de uma série de fatores cognitivos e motores, como já sugerido. Caso o desempenho do aprendiz não atinja o seu ápice, o uso de estratégias articulatórias se tornará o caminho mais previsível à realização desses fonemas.

\section{0 professor de língua estrangeira e o conhecimento fonético}

Como um dos principais objetivos do aprendiz é fazer-se comunicar oralmente de forma satisfatória - e, se possível, de modo bastante semelhante a um nativo - na L2, o professor não pode desconsiderar que o aporte da ciência fonético-fonológica pode trazer uma significativa colaboração à prática cotidiana do processo de 
aquisição linguística. Embora, muitas vezes, o trabalho intuitivo nessa área consiga produzir resultados até satisfatórios, não se pode ignorar que a habilidade de aplicar o conhecimento técnico apropriado às múltiplas situações envolvendo o aprimoramento da pronúncia produzirá resultados mais rápidos e eficientes.

Ao lidar com as dificuldades de pronúncia e aplicar as técnicas de aprimoramento articulatório apropriadas, o professor de L2 utiliza conhecimentos fundamentais relacionados à fisiologia articulatória do aparelho fonador, ao comportamento acústico dos segmentos sonoros e, com o avanço da tecnologia, pode também contar com programas computacionais que permitem tanto um diagnóstico mais preciso dos problemas enfrentados na pronúncia pelo aprendiz quanto um encaminhamento para atingir melhores resultados.

A disposição e a própria flexibilidade dos órgãos envolvidos na produção da fala impõem limitações à produção de determinados segmentos. No quadro consonantal do Alfabeto Fonético Internacional (cf. o Handbook of the International Phonetic Association, p. IX), as células em cinza indicam que a combinação de um modo com um determinado ponto de articulação não é passível de realização, por razões de limitação mesmo fisiológica. Por exemplo, a produção de um tap implica o contato ligeiro e direto do articulador ativo com um ponto na parte superior do trato vocal (no caso do tap alveolar, esse contato se estabelece entre o ápice da língua e a região alveolar) (LADEFOGED; MADDIESON, 1996, p. 231). Por mais flexível que a língua possa ser, não é possível que esse contato se dê, por exemplo, com a região velar e, simultaneamente, ocorra a gesticulação necessária à produção de um tap. As demais células em branco, no Alfabeto, indicam a possibilidade de essas combinações entre modo e ponto de articulação ocorrerem, embora não tenham sido ainda atestadas em nenhuma língua natural.

Acompanhar a aquisição fonético-fonológica de um aprendiz de L2 torna-se particularmente interessante ao se constatar que as dificuldades articulatórias manifestadas explicitam os mecanismos envolvidos na realização dos fonemas. Mesmo o professor nativo de uma L2 muitas vezes não atenta para esses mecanismos, pelo simples fato de, por ser nativo, eles não lhe oferecerem dificuldades articulatórias. Ao deparar com e analisar o processo de aquisição de sua própria 
língua por um estrangeiro, desencadeia-se uma consciência metalinguística que proporcionará ao profissional uma melhor desenvoltura na condução do aprendizado. Ao deparar com um aprendiz anglofalante que, ao pronunciar a palavra 'dedo', no português, produz o desvozeamento da primeira consoante oclusiva alveolar, explicita-se a consciência do papel da vibração das pregas vocais durante a realização de um segmento vozeado. Ao deparar com um aprendiz brasileiro que, ao pronunciar a palavra 'Tasse', no alemão, não produz a aspiração da consoante oclusiva surda, atenta-se para o modo de articulação fricativo, e a necessidade de realização de um ligeiro segmento fricativo acompanhando o oclusivo para que a pronúncia se assemelhe à de um nativo dessa língua. Da mesma forma, a pronúncia da palavra 'loja', do português, por um aprendiz francofalante que realize a primeira vogal não tão aberta quanto o faz um nativo brasileiro evidenciará que a altura das vogais no trato vocal interfere em sua qualidade, permitindo identificar quem pronunciou a palavra como estrangeiro.

A conformação do trato vocal, gerada a partir da gesticulação produzida durante a fala, possibilita uma caracterização acústica específica para cada segmento sonoro. Como o trato vocal superior se apresenta como uma caixa de ressonância eficiente e maleável, os diferentes formatos que assume permitem que as ondas sonoras se concentrem em determinadas frequências, evidenciando-se o que se conhece como "formantes" (para maiores detalhes, cf. FANT, 1970).

A fonte sonora primária são as pregas vocais. Sua frequência de vibração, por ser a mais baixa de um determinado segmento, corresponde ao formante que se denomina "F0", ou frequência fundamental, que corresponde à melodia da voz. Sua vibração produzirá um som vozeado. Ao se propagarem na caixa de ressonância que é o trato vocal, as ondas sonoras concentram-se em determinadas frequências, produzindo-se o primeiro (F1), o segundo (F2), o terceiro (F3) e, potencialmente, infinitos formantes. Como há uma correlação entre a conformação do trato vocal e a possibilidade de concentração de energia em determinadas frequências sonoras, percebe-se que cada segmento sonoro apresentará, em princípio, uma configuração formântica diferente do outro. A título de exemplificação, pode-se considerar as sete vogais orais tensas do português brasileiro. 
Segundo a indicação do Alfabeto Fonético Internacional, a classificação das vogais leva em consideração sua anterioridade/ posterioridade e seu grau de elevação no trato vocal. Como será apresentado mais à frente, há uma relação direta entre essa gesticulação e os valores formânticos, especialmente os de F1 e de F2. De uma forma geral, é possível perceber que, quanto mais distanciados estiverem F1 e F2, mais anterior será a vogal; quanto mais próximos, maior será o grau de posteriorização, como ilustrado na figura 1 . Observe-se que, nessa figura, a aproximação de F1 e de F2 na vogal [u] é tamanha que faz com que se sobreponham, dando a impressão de que, na parte inferior, está representado apenas um formante.

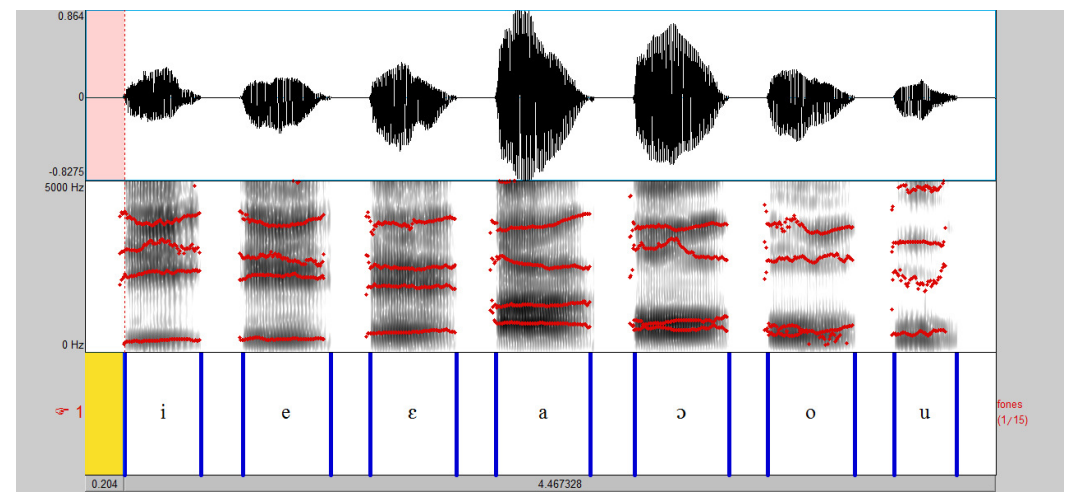

Fig. 1 - Oscilograma e espectrograma, com alinhamento sonoro, representando a pronúncia das sete vogais orais tensas do português brasileiro por um falante nascido no Estado do Espírito Santo. Os tracejados horizontais, no espectrograma (parte central da figura) representam os formantes: F1 corresponde ao mais baixo

O trabalho de Lindbloom e Sundberg (1971) investiga os correlatos acústicos do movimento dos lábios, da língua, da mandíbula e da laringe. De forma esquemática, a relação geral entre a articulação e os fatores acústicos pode ser entendida em cinco etapas:

1. Abertura da mandíbula - elevação de F1 e elevação de F2 caso a língua esteja retraída em direção ao palato mole; F3 pode sofrer elevação abrupta se a mandíbula estiver 
moderadamente aberta e a língua, voltada para a região do palato;

2. Movimentação da língua na direção antero-posterior - F1 sofre modesta elevação (em torno de $200 \mathrm{~Hz}$ ); F2 sofre uma grande queda com o movimento da língua de uma posição anterior para uma posição neutra;

3. Formato da língua - verifica-se o controle do grau de constrição do trato vocal, assumindo-se que a mandíbula mantenha uma posição constante; F1 sofre pouca influência; F2 sofre queda substancial com o aumento da constrição;

4. Arredondamento dos lábios - produz o abaixamento geral de todos os formantes, especialmente F2 e F3;

5. Abaixamento da laringe-com o alongamento do trato vocal, os formantes tendem a sofrer queda. A influência da movimentação da laringe ocorre mais sobre F2 e F4 do que sobre F3.

Esse comportamento formântico, em linhas gerais, permite que o professor de L2 identifique os correlatos articulatórios que estejam influenciando de forma mais direta a qualidade sonora da pronúncia dos segmentos pelo aprendiz. A partir dessa identificação, será possível, então, planejar atividades motoras que auxiliem no condicionamento mais apropriado do trato vocal, que tenderá a assumir as configurações mais precisas necessárias à realização de cada fonema da L2. A elaboração dessas atividades, provavelmente, assumirá como ponto inicial a gesticulação necessária aos fonemas da própria L1 do aprendiz que, de forma gradativa e por meio do uso de estratégias de reparo, perceberá as peculiaridades de um e de outro sistema linguístico, adaptando os movimentos dos articuladores em seu trato vocal às particularidades gesticulatórias da L2.

Com o avanço tecnológico e a popularização dos instrumentos, o procedimento de representação acústica da fala tornou-se acessível a praticamente qualquer profissional do ensino. Enquanto, no passado, a análise acústica dependia de equipamentos específicos e volumosos, acondicionados em laboratórios, presentemente é possível efetuar os mesmos procedimentos com um computador portátil, um microfone e um programa para esse fim específico. Dessa forma, o professor de L2 poderá manter, em sua sala de aula, esse equipamento básico e, detectadas as particularidades de pronúncia mais recorrentes dos 
aprendizes, como um todo, ou de algum deles, individualmente, proceder à gravação da fala, isolar a palavra que contém o segmento problemático específico e comparar a configuração espectrográfica gerada pela fala do aprendiz com uma de referencial (no caso, a mesma palavra pronunciada por um falante nativo da língua).

Embora o som seja uma entidade física, a sensação ao lidar com ele assume contornos muito mais abstratos do que concretos. Como tudo o que se pode visualizar torna-se mais palpável, mais facilmente analisável, a representação espectrográfica da realização sonora de uma palavra permitirá uma percepção menos impressionística da parte do aprendiz em relação à forma como ele próprio articula as palavras da L2. Naturalmente, os detalhes de uma análise espectrográfica são de interesse específico do professor, que é o técnico com formação no assunto; a apresentação de um espectrograma, em sala de aula, focalizará aspectos mais amplos, de mais fácil percepção para o observador não especializado. Um exemplo desse uso pode ser o da pronúncia da consoante fricativa glotal desvozeada $[\mathrm{h}]$ na palavra inglesa 'help' por um francês. O sistema fonológico do francês possui, como único rótico, a consoante fricativa uvular vozeada [B]. Por se tratar de um segmento estranho ao francês, $[\mathrm{h}]$ provavelmente seria realizado por meio de [b], numa estratégia de substituição (cf. seção 2, acima). No entanto, muitos franceses omitem esse segmento, realizando a pronúncia [عlp] no lugar da prescrita [help]. Muitas vezes, por mais que o professor chame a atenção para esse fato, e reproduza a pronúncia correta, o aprendiz persiste na inadequação, pela simples razão de, por estar cognitivamente condicionado pela ausência desse segmento em seu sistema linguístico materno, não conseguir percebê-lo. Como a consoante fricativa desvozeada [h] apresenta uma configuração espectrográfica típica (a ausência de periodicidade no sinal sonoro gera uma imagem semelhante à de ruído, semelhante ao que se verificava na tela de televisão quando havia interrupção na transmissão do sinal), a visualização do contraste entre as duas pronúncias (uma delas, a do próprio aprendiz) fará com que ele perceba que o segmento [h] realmente é realizado e, a partir de então, muito provavelmente, passará a utilizá-lo, senão de forma perfeita, pelo menos de forma aproximada.

Existem alguns programas computacionais que, embora destinados aos profissionais que lidam especificamente com a fonética 
acústica, prestam-se muito bem ao uso em sala de aula. Um deles, o WinPitch, desenvolvido pela Pitch Instruments Inc., possui, inclusive, uma versão especificamente voltada para o ensino de língua. Um outro exemplo é o Praat, desenvolvido por Boersma e Weenink (2006), de interface menos amigável, mas mais difundido entre os profissionais da área. As figuras utilizadas neste trabalho foram geradas com o Praat.

\section{Análise de casos}

A instrumentalização da fonética no ensino de L2 pode trazer benefícios imediatos ao aprendizado, acelerando a percepção de detalhes que, de forma tradicional, provavelmente dependeriam de um tempo muito mais longo para serem percebidos e internalizados. As três situações apresentadas a seguir foram verificadas na interface, respectivamente, do inglês, do alemão e do francês com o português. Os dados foram colhidos junto a estudantes estrangeiros que, à época, estavam vinculados ao Programa Linguístico-Cultural para Estudantes Internacionais (PLEI), em realização na Universidade Federal da Paraíba. Esses são exemplos de como se pode diagnosticar/caracterizar problemas de pronúncia específicos.

\section{a) $\mathbf{O}$ desvozeamento no inglês}

Embora o sistema fonológico do inglês apresente as mesmas consoantes oclusivas que o do português ([p b t d k g]), a realização desses segmentos assume particularidades próprias em um e em outro idioma. No caso do inglês, as oclusivas vozeadas [b d g] apresentam pouco ou nenhum vozeamento durante o período de oclusão típico desses segmentos, exceto quando eles se encontram em posição intervocálica (LADEFOGED, 1999, p. 43). A pronúncia da palavra 'dedo' pelo aprendiz estadunidense, como indicado na figura 2, soou como se tivesse sido pronunciado o logátomo "teto" (com a vogal $[\mathrm{e}]$, não a vogal $[\varepsilon])$. Naturalmente, considerando-se que a palavra seria utilizada em um contexto comunicativo, o desvozeamento, nesse caso específico, não implicaria impedimento à transmissão da informação correta, mas denunciaria a origem estrangeira de seu emissor.

Espectrograficamente (considerando-se, portanto, a parte horizontal medial da figura), o vozeamento é perceptível pelo menos 
de duas formas. Por se tratar de um som vozeado, haverá vibração das pregas vocais, cujo correlato acústico é a frequência fundamental, ou F0. No comando específico do programa Praat, é possível acionar a exibição estilizada da linha de F0, representada, na figura 2, pela linha modulada horizontal que atravessa os segmentos [edo], mas não o segmento inicial. A F0 se manifesta apenas nos segmentos vozeados, o que implica dizer que, se a curva não se manifestou sobre a posição destinada à realização da consoante /d/, no início da palavra, esse segmento não apresentou vozeamento. Observe-se que, na segunda ocorrência dessa consoante, em posição intervocálica, como previsto, o vozeamento ocorreu.

Outra forma de verificar se houve ou não vibração das pregas vocais em um segmento é observar a barra de vozeamento, que corresponde à barra inferior extrema no espectrograma. Se essa barra for representada em tom de cinza mais escuro (admitindo-se gradiências), terá ocorrido a vibração. $\mathrm{Na}$ figura 2, percebe-se que ela é bem escura ao longo de ambas as vogais (segmentos eminentemente vozeados); na primeira realização de /d/, ela não se manifesta; na segunda, manifesta-se de forma menos intensa, mas se manifesta.

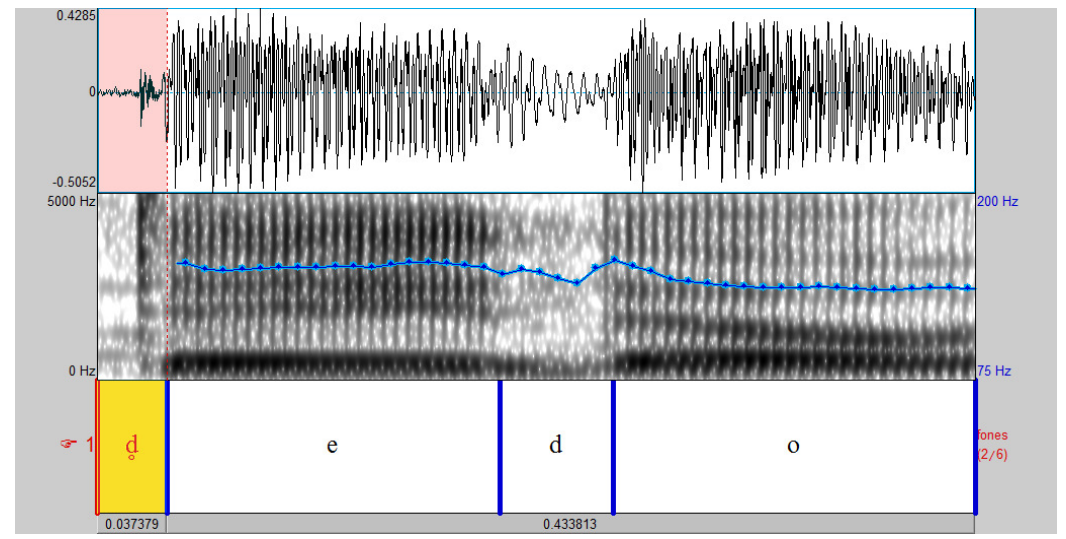

Fig. 2 - Oscilograma e espectrograma representando a pronúncia da palavra ‘dedo’ por informante estadunidense de nível pré-intermediário no aprendizado do PB. A área destacada corresponde à realização desvozeada da consoante oclusiva alveolar /d/ 


\section{b) A aspiração no alemão}

O sistema linguístico alemão, além de contar com as mesmas consoantes oclusivas do português, conta também com uma oclusiva glotal surda [?]. Além dessa particularidade, as consoantes oclusivas desvozeadas /p t k/ são aspiradas quando não ocorrem precedidas de uma consoante fricativa dentro da mesma palavra, nem são seguidas por uma consoante nasal silábica. Essa aspiração será mais forte antes de uma vogal acentuada, e mais fraca em palavras funcionais não acentuadas (KOHLER, 1999, p. 87).

Ao pronunciar a palavra 'batata' no português, como representado na figura 3, o aprendiz alemão transferiu essa característica da realização das consoantes oclusivas desvozeadas de sua língua para o português (observe-se também que, de forma semelhante ao que ocorreu com o exemplificado na figura 2, houve desvozeamento na realização da consoante /b/, no início da palavra). A aspiração é verificada sob a forma da consoante fricativa glotal surda $[\mathrm{h}]$, presente entre a barra de explosão do fone oclusivo [t] e a vogal [a], tanto na última quanto na penúltima sílaba da palavra. Observe-se que, no espectrograma, não há uma regularidade de forma (como nas vogais), lembrando um ruído (característico das consoantes fricativas). Embora também no português se verifique um espaçamento entre a barra de explosão da oclusiva e o início da vogal ${ }^{1}$, sua duração é consideravelmente menor, passando despercebida ao ouvido, diferentemente do que ocorre com a aspiração.

${ }^{1}$ Esse espaçamento corresponde ao VOT - Voice Onset Time. 


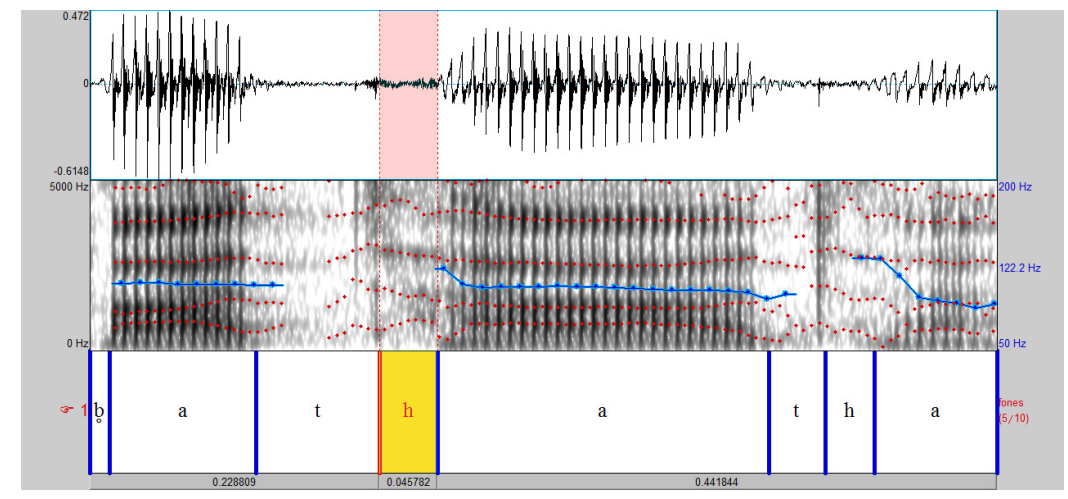

Fig. 3 - Oscilograma e espectrograma representando a pronúncia da palavra 'batata' por informante alemão de nível básico no aprendizado do PB. A área destacada corresponde à aspiração da consoante oclusiva alveolar desvozeada /t/

\section{c) A altura das vogais no francês}

Um símbolo fonético pode ser utilizado para representar uma vogal que, rigorosamente, apresenta características distintas em um idioma e em outro. Essas peculiaridades são perceptíveis ao ouvir a pronúncia dessa pretensamente "mesma" vogal por nativos de línguas diferentes.

No caso do francês, percebe-se que, diferentemente do que ocorre no português, manifestam-se vogais anteriores arredondadas (FOUGERON; SMITH, 1999, p. 78). A própria realização das vogais francesas assume uma conformação bastante peculiar, se assumido o referencial das vogais do português brasileiro. Muitas vezes, o professor, ao ouvir a pronúncia de uma palavra na L2 por um francofalante, percebe que a vogal utilizada não está numa altura semelhante ao que se esperaria para essa vogal na L2, mas não consegue precisar em que posição o aprendiz está articulando o segmento.

Uma possibilidade de identificar esse posicionamento das vogais com maior precisão é construir um triângulo vocálico utilizando as realizações do aprendiz, de forma a sobrepor esse triângulo a um outro que sirva de referencial para a L2. A figura 4 exemplifica esse procedimento. As vogais identificadas na cor preta correspondem às vogais de uma falante nativa do português brasileiro; na cor vermelha, 
identificam-se as vogais de uma francofalante, ao pronunciar palavras do português. Como se pode perceber, a vogal [u] da francofalante mostra-se mais anteriorizada do que a da brasileira, assim como a vogal [a] ocupa uma posição muito mais elevada. É interessante observar, ainda, que as vogais médias altas [e o] e baixas [ $\varepsilon$ o] confluem para um mesmo ponto intermediário, o que as torna assemelhadas. $\mathrm{Na}$ pronúncia do português brasileiro, esse tipo de comportamento evidencia claramente a natureza estrangeira da falante, fazendo com que as vogais ortográficas "e", nas palavras 'dedo' e 'martelo'; e "o", nas palavras 'bolo' e 'loja' soem de forma respectivamente idêntica - e nenhuma delas de forma semelhante ao que se observa no português brasileiro.

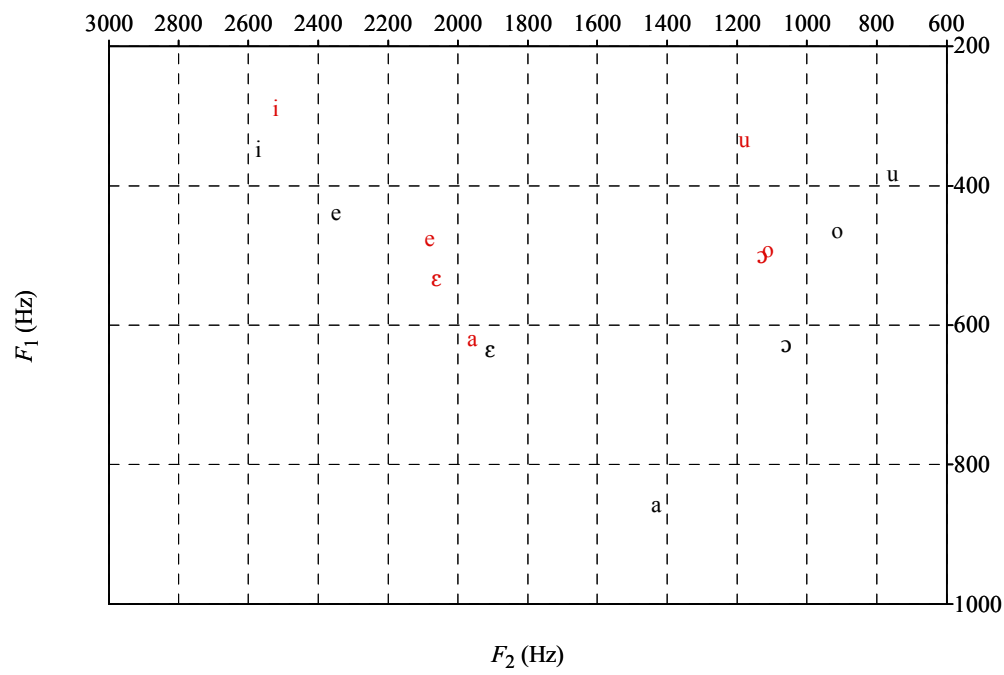

Fig. 4 - Sobreposição dos triângulos vocálicos de uma brasileira e de uma informante francesa de nível intermediário no aprendizado do PB. A parte frontal da figura corresponde à parte frontal do trato vocal.

\section{Considerações finais}

O procedimento de análise dos três casos na seção anterior não constitui uma solução per se para as dificuldades de pronúncia dos 
aprendizes. Como sugerido na seção (3), o uso de um programa de análise acústica permitirá a materialização do problema, por meio da visualização do comportamento acústico-articulatório dos segmentos sonoros. É possível que a visualização de imagens, como as exemplificadas, desperte no aprendiz a noção do que ocorre no interior de seu trato vocal quando pronuncia os segmentos da L2, permitindo que ele próprio encontre caminhos para uma pronúncia mais aprimorada. Esse diagnóstico, ao mesmo tempo, subsidiará o trabalho do professor, que poderá, então, planejar atividades práticas que conduzam a gesticulação oral do aprendiz no sentido desejado.

É necessário que se dê uma atenção mais direcionada e mais técnica ao ensino da pronúncia nas aulas de L2. Como indica Lima Jr. (2010), resultados muito positivos têm sido atingidos quando se dedica uma parcela do tempo das aulas a esse fim. Seus dados demonstram que, com 16 sessões de intervenção de 15 minutos cada, considerandose uma carga horária de 35 aulas de 1 hora e 40 minutos cada (portanto, $7 \%$ do tempo total, sem a necessidade de aulas complementares de pronúncia), aprendizes brasileiros do inglês apresentaram uma melhoraria muito grande em sua pronúncia. Parece razoável, portanto, pressupor que o mesmo tenderá a ocorrer também no ensino de qualquer outro idioma como L2.

\section{Referências}

BOERSMA, P.; WEENINK, D. Praat: doing phonetics by computer (Versão 5.1.31) [Programa computacional]. 2006. Disponível em: $<$ http://www.praat.org/.>

CARVALHO, A.M. Português para falantes de espanhol: perspectivas de um campo de pesquisa. Hispania, v. 85, n. 3, p. 597-608, 2002.

DUTRA, A. Aquisição do português como língua estrangeira: fenômenos de variações no âmbito fonológico. 2008. Tese (Doutorado em Linguística e Língua Portuguesa) - Universidade Estadual Paulista Júlio de Mesquita Filho, Araraquara. 2008. 
ECKMAN, F.R. From phonemic differences to constraint rankings: research on second language phonology. Studies in Second Language Acquisition, Cambridge University Press, v. 26, n. 4, p. 513-549, 2004.

FACE, T.L. Intervocalic rhotic pronunciation by adult learners of Spanish as a second language. In: KLEE, C.A.; FACE, T.L. Selected proceedings of the 7th Conference on the Acquisition of Spanish and Portuguese as First and Second Languages. Somerville, MA: Cascadilla Proceedings Project, 2006.

FANT, G. Acoustic theory of speech production. With calculations based on X-ray studies of Russian Articulations. The Hague: Mouton, 1960.

FOUGERON, C.; SMITH, C.L. French. In: THE INTERNATIONAL PHONETIC ASSOCIATION. Handbook of the International Phonetic Association. A guide to the use of the International Phonetic Alphabet, Cambridge: Cambridge University Press, 1999.

KOHLER, K. German. In: THE INTERNATIONAL PHONETIC ASSOCIATION. Handbook of the International Phonetic Association. A guide to the use of the International Phonetic Alphabet, Cambridge: Cambridge University Press, 1999.

LADEFOGED, P. American English. In: THE INTERNATIONAL PHONETIC ASSOCIATION. Handbook of the International Phonetic Association. A guide to the use of the International Phonetic Alphabet, Cambridge: Cambridge University Press, 1999.

.; MADDIESON, I. The sounds of the world's languages. Oxford: Blackwell Publishers, 1996.

LIMA JR., R.M. Uma investigação dos efeitos do ensino explícito da pronúncia na aula de inglês como língua estrangeira. Revista Brasileira de Linguística Aplicada, Belo Horizonte, v. 10, n. 3, p. 747-771, 2010.

LINDBLOOM, B.E.F;; SUNDBERG, J.E.F. Acoustical consequences of lip, tongue, jaw, and larynx movement. Journal of the Acoustical Society of America, v. 50, n. 4B, p. 1166-1179, 1971. 
OLIVEIRA, C.C. Aquisição das consoantes róticas no português brasileiro e no espanhol: um estudo comparativo. 2006. Tese (Doutorado em Letras) Pontifícia Universidade Católica do Rio Grande do Sul, Porto Alegre. 2006.

PITCH INSTRUMENTS INC. WinPitch. Disponível em: < http:// www.winpitch.com/>.

SANT'ANNA, M.R. As interferências fonológicas no inglês como língua estrangeira para os falantes do português do Brasil. Dialogia, v. 2, p. 57 70, out. 2003.

A pronuncia das consoantes inglesas em final de vocábulo por falantes brasileiros. 2008. Tese (Doutorado em Semiótica e Linguística Geral) Universidade de São Paulo, São Paulo. 2008.

THE INTERNATIONAL PHONETIC ASSOCIATION. Handbook of the International Phonetic Association. A guide to the use of the International Phonetic Alphabet, Cambridge: Cambridge University Press, 1999.

WERTZNER, H.F.; PAGAN-NEVES, L.O.; CASTRO; M.M. Análise acústica e índice de estimulabilidade nos sons líquidos do português brasileiro. Revista CEFAC, v. 9, n. 3, p. 339-350, 2007.

ZIMMER, M.C. Um estudo conexionista da transferência do conhecimento fonético-fonológico do PB (L1) para o inglês (L2) na leitura oral. In: POERSCH, M.; ROSSA, A. Processamento da linguagem e conexionismo. Santa Cruz: EDUNISC, 2007. p. 105-154. 